\title{
Support to women who denounce experiences of violence based on her social network ${ }^{1}$
}

\author{
Letícia Becker Vieira² \\ Ivis Emília de Oliveira Souza ${ }^{3}$ \\ Florence Romijn Tocantins ${ }^{4}$ \\ Florentina Pina-Roche ${ }^{5}$
}

Objective: to analyze the possibilities of help/support through the mapping and acknowledgement of the social network of women who denounce experiences of violence at a Police Precinct for Women. Method: qualitative study based on the theoretical-methodological framework of Lia Sanicola's Social Network, through interviews with 19 women. Results: the analysis of the network maps evidenced that the primary social network was more present than the secondary on and, despite consisting of significant relations, it demonstrates limitations. The women access the secondary network occasionally in the violence problem and/or its repercussions in their life and health. The discrete presence of the health network in the composition of the social network was revealed and, when mentioned, the relation between the health professional and the woman was characterized as fragile. Conclusion: the importance of the social network relates to the creation of spaces of help/support for the women beyond the moment of the aggression, which accompany them throughout their process of emancipation from an experience annulled by violence, considering that each woman acts and makes decisions in the relational context when she is ready for it.

Descriptors: Women's Health; Violence Against Women; Social Support.

\footnotetext{
${ }^{1}$ Paper extracted from doctoral dissertation "The woman who experience the violence complaint and the relation with her social network: perspectives to caring in health", presented to Escola de Enfermagem Anna Nery, Universidade Federal do Rio de Janeiro, Rio de Janeiro, RJ, Brazil. Supported by Conselho Nacional de Desenvolvimento Científico e Tecnológico (CNPq), Brazil, process \# 143319/2011-6.

2 PhD, Adjunct Professor, Escola de Enfermagem, Universidade Federal do Rio Grande do Sul, Porto Alegre, RS, Brazil.

3 PhD, Full Professor, Escola de Enfermagem Anna Nery, Universidade Federal do Rio de Janeiro, Rio de Janeiro, RJ, Brazil.

${ }^{4} \mathrm{PhD}$, Full Professor, Escola de Enfermagem Alfredo Pinto, Universidade Federal do Estado do Rio de Janeiro, Rio de Janeiro, RJ, Brazil.

${ }^{5}$ PhD, Full Professor, Faculdad de Enfermería, Universidad de Murcia, Murcia, Spain.
}

Corresponding Author:

Letícia Becker Vieira

Universidade Federal do Rio Grande do Sul. Escola de Enfermagem

Rua São Manoel, 963

Bairro: Rio Branco

CEP: 90620-110, Porto Alegre, RS, Brasil

E-mail: lebvieira@hotmail.com
Copyright $\odot 2015$ Revista Latino-Americana de Enfermagem This is an Open Access article distributed under the terms of the Creative Commons Attribution Non-Commercial License (CC BY-NC).

This license lets others distribute, remix, tweak, and build upon your work non-commercially, and although their new works must also acknowledge you and be non-commercial, they don't have to license their derivative works on the same terms. 


\section{Introduction}

Violence against women by intimate partners is an important conditioning factor of female health, as well as a serious public health problem, due to the magnitude of the epidemiological data and their social and economic impacts in the lives of the women and other persons involved. It is part of a multifactorial construction, a social, political, economic and health problem that requires the integration of knowledge and services from different areas $^{(1-2)}$.

The Brazilian national policy of coping with violence against women, established in 2008, has contributed to appoint guidelines and support actions to prevent, confront and cope with violence against women. Among these guidelines, the concept of coping and care network as a strategy to combat the violence is focused on. The construction of the care network aims to describe the complexity of violence against women and the multidimensional nature of the problem, which runs through different areas, such as health, education, public safety, social services and culture, among others ${ }^{(3)}$.

Nevertheless, a trend towards the isolation from the network services and towards disarticulation among the different care levels continues to exist in order to cope with this issue. Work in the formal and informal intersectorial network therefore emerges as a strategic route to overcome this trend towards fragmentation ${ }^{(3-4)}$.

A study on the women's trajectories in search of resources to break with the experiences of violence identify the lack of support, revictimization and prejudiced attitudes by people who should welcome them, suggesting that, despite the existence of specialized services, their isolated action does not avoid the women's exposure to further violence ${ }^{(4-5)}$. The women's trajectory in search of help for the rupture is a current social and health problem that refers to the academic context, but also to the social operators, making it extremely pertinent to assess the women's peregrination through the services as well as to critically reflect on these experiences ${ }^{(4)}$.

It is acknowledged that the social network conception is an alternative to address the dynamics of the social relations women in situations of violence establish with their environment and the services that welcome them, constituting a possible trajectory for professional understanding and activity, focused on the complexity of the social life involved in violence against women $^{(6)}$. In that sense, the network conception has been recognized in the political-care sphere as well as in scientific studies as an effective strategy to cope with the violence ${ }^{(4-6)}$.

The social network is a set of people, organizations or social institutions that are connected by some kind of relationship. It is defined as a set of interpersonal and social relations. From this network, the person can receive emotional, material, service and informational help. The social networks can be primary or secondary and differ according to the types of exchanges that occur among individuals, marked by reciprocity, right, money or a combination of these ${ }^{(7)}$.

In the primary networks, the bonds established are characterized by relations of parenthood, friendship or neighborhood, and rest on reciprocity and trust. The secondary networks (SN) can be formal and/ or informal, related to the service sector, to the market, or mixed. They mutually differ by the type of exchange: reciprocity, right, money or a combination of these means. The formal SN consists of official social institutions and is characterized by service provision according to people's demands and exchange based on rights. In the informal SN, on the other hand, the bond rests on solidarity. Secondary networks from the service sector are associations or organizations constituted by private persons, which belong to the service provision context and are characterized by exchanges based on rights as well as by solidary. A market-related $\mathrm{SN}$ refers to profitable economic activities, and its existence is closely linked to money and profit(7-8).

Despite the finding that social networks are important to cope with violence, as they offer psychological, emotional, care, social and often financial support to the women, and despite the urgent need to strengthen them, the identification and configuration of these networks and their contributions to the women's empowerment in order to break with violent relationships are still lacking ${ }^{(6,9)}$. This discussion also causes tension in the health area, in view of the observation that the role that is expected from this area as an articulator of the network and of actions to cope with the violence is not achieved, as the health services still do not constitute an effective entry door for the cases in question ${ }^{(4-6,9)}$.

In view of these findings and when contextualizing the knowledge and activity sphere of the health and Nursing area as a part of the secondary social care network for women in situations of violence, the analysis of the health services' inclusion into the field 
of violence and the social network (considered as a political, organizational and care strategy to cope with and counter the violence) can be combined with the dimension of devising this network in view of comprehensive health care.

In that sense, the objective in this study was to analyze the possibilities of help/support through the mapping and acknowledgement of the social network of women who denounce experiences of violence at a Police Precinct for Women (DPPM).

\section{Method}

A qualitative and descriptive study was undertaken, based on the theoretical and methodological framework of Lia Sanicola's Social Network ${ }^{(7)}$. The participants were 19 women who denounced violence experienced at a Police Precinct for Women in a city in the South of Brazil. The choice to obtain the research participants from this public service, which is part of the women's formal secondary social help/support network because, in this scenario, they understand violence as a legal infraction, differently from the approach of women who experience violence in health services, who often hide their violent experiences. Therefore, the following were considered as inclusion criteria: age range between 18 and 59 years (the parameter for this age range relates to the legislation and the specialized precincts in the city) and women who, in the records of the violent event, indicated their former partner, husband or boyfriend as the aggressor.

The researcher entered the research area through community service activities developed in partnership with the DPPM and prior meetings with the service team. The women were randomly contacted in the waiting room of the precinct and, after they had accepted to participate, the interviews were held after they had filed a complaint on the violent event. Only one woman refused to participate in the research. The closing of the sample was based on theoretical saturation, when the findings converged with the proposed objective(10). The data were produced between June and November 2012 at a private room, so as to guarantee the participants' privacy. The average length of the interviews was 45 minutes.

An individual's relationship network can be analyzed through the elaboration of the social network map, based on qualitative studies that permit understanding the dimension, the way the social links are established, as well as the meanings of human actions and relations; favoring a comprehensive look on the social context the people experience ${ }^{(8)}$.

The knowledge process of the women's social context in this study allowed them to participate actively in the elaboration of their social network map. Therefore, a semistructured script was used with questions about sociodemographic characteristics and relational context. To elaborate the social network map, each research participant was asked to list the people she knew and who were present in her life, and then indicate/comment on the people that offered help/ support in the violent situation she experienced. At the same time, the participants were asked to help the researcher to make a drawing, representing the people or families who were close or distant from their family context, the presence of professional bonds and the institutions she attended or from which she received any benefit, indicating their position towards her. For that moment, geometrical figures were used that represented her network members, and another that graphically represented the lines corresponding to the type of bond established. These indicators permit analyzing the network structure ${ }^{(7-8)}$.

In that sense, the goal was to understand how the links were established in the relational context of the people in the network and to problematize, based on the women's discourse, the configuration of this network. Among others, the analysis was based on indicators of: range - refers to the number of people present and permits affirming whether a network is small, medium or large; and density - refers to the number of people who know one another ${ }^{(7-8)}$. The data from each participant were audiorecorded and fully transcribed, constituting the analysis corpus. At the end, a network map was elaborated that represented the members and bonds' shared characteristics in the women's 19 networks, that is, the construction of these women's typical social network. That construction was based on Alfred Schutz' concept of typification, represented by all participants' shared (typical) characteristics ${ }^{(11)}$.

Approval for the research project was obtained from the Institutional Review Board (Protocol19004/20012) and all participants signed the Informed Consent Form, in compliance with National Health Council Resolution $466 / 2012$. To guarantee the participants' anonymity, the letter $\mathrm{W}$ was used for woman, followed by progressive numbering. 


\section{Results}

Concerning the participants' characteristics, the age range was between 18 and 59 years; varying between no experience of motherhood and having 10 children; the predominant education level was finished secondary education; most participants lived in the urban region and have a paid job. Most women have a stable relationship with their current partner. The prevalent length of the relationship with the partner whom they accused of violence was more than 10 years. The mean number of complaints filed against their former partner was three, and the place of the aggression was their own home.

The social network map of the women who denounce their violent experiences evidence a mediumrange network, followed by small networks, but with a predominance of few relationships among the network members, i.e. low density. It is highlighted that the effective distance and the level of intimacy of most people in the network is family-related, being individuals who live near the woman.

It was verified that most women refer to the presence of a strong and normal bond ${ }^{(7)}$ with members of their primary network, especially with their mother, father, friends, neighbors, aunts/uncles, grandmothers, current boyfriends, co-workers; the female gender was predominant in the network, revealing that these are the people most involved with them during the situations of violence. The relationship with the former partner is characterized by frailty, conflict or rupture. The former partner's bonds with the other primary social network members of the women are also marked by conflicts and ruptures. The map reveals that the main cause of networks with low levels of range and density (ruptures with neighbors, friends, co-workers, relatives and even with children and the fragile bonds) is the partner's imposition due to the network members' distancing, for different reasons the women list as jealousy, people's negative judgment, non-acceptance of the relatives and the matter of children (when the woman is not the children's legal guardian). These situations forward the women to social isolation in her relationship network.

The participants reveal a frail and ruptured relationship with the family members from the primary network, alleging that, often, they do not relate with these network members or do not contact them in search of help, and attribute this to the fact that they do not want these family members to judge them. They reported that, because of the violent situation experienced, they needed to constantly change their address to live without violence and not be killed by their partner. The women considered this address change as a factor that hampers the relationships with their primary social network because of the physical distance and daily contact.

As regards the people in their social network engaged in the violent situation and from whom they sought help, these were relatives, friends, neighbors and co-workers, in parallel with the secondary network members, and they revealed a precarious help relationship for the women, as the services who deliver care to women in violent situations are reminded, but not considered and acknowledged as effective help for their social and health demands, as these services are punctual and they do not engage in the process of coping with the violence.

As regards the formal secondary social network, this consisted of care services for the women and their children. The following were listed: the Police Precinct for Women, Tutelary Council, school, Military Brigade, primary health care unit, shelter house, medical-legal institution, Prosecutor's Office (Court for Childhood and Youth), mobile emergency service, emergency care service and psychiatric sector in hospital. As regards the secondary service network, this includes religious entities (evangelical church, catholic church, Spiritual Center and Umbanda Center) and non-governmental organizations that deliver care to children in vulnerable situations. The mixed secondary network, then, consisted of legal advice from law services and advocacy and private psychiatric and psychology services.

The secondary network was identified and contextualized as broader and more diversified, according to the woman's need to seek intersectorial help, like in public safety, health, justice, social services and support with matters related to the children's guardianship and pension. The health services were summoned according to the physical severity of the violence. Some women indicated that they did not remember whether they were attended by the emergency services or not, given the critical health situation they were in when they entered the services.

In the relationship with the professionals who are active at the services in the secondary social network, the women's little involvement with these professionals was found. The relations are established punctually, hardly expressing bonding and trust. The typical social network of the women in this study is constituted based on the map (Figure1): 


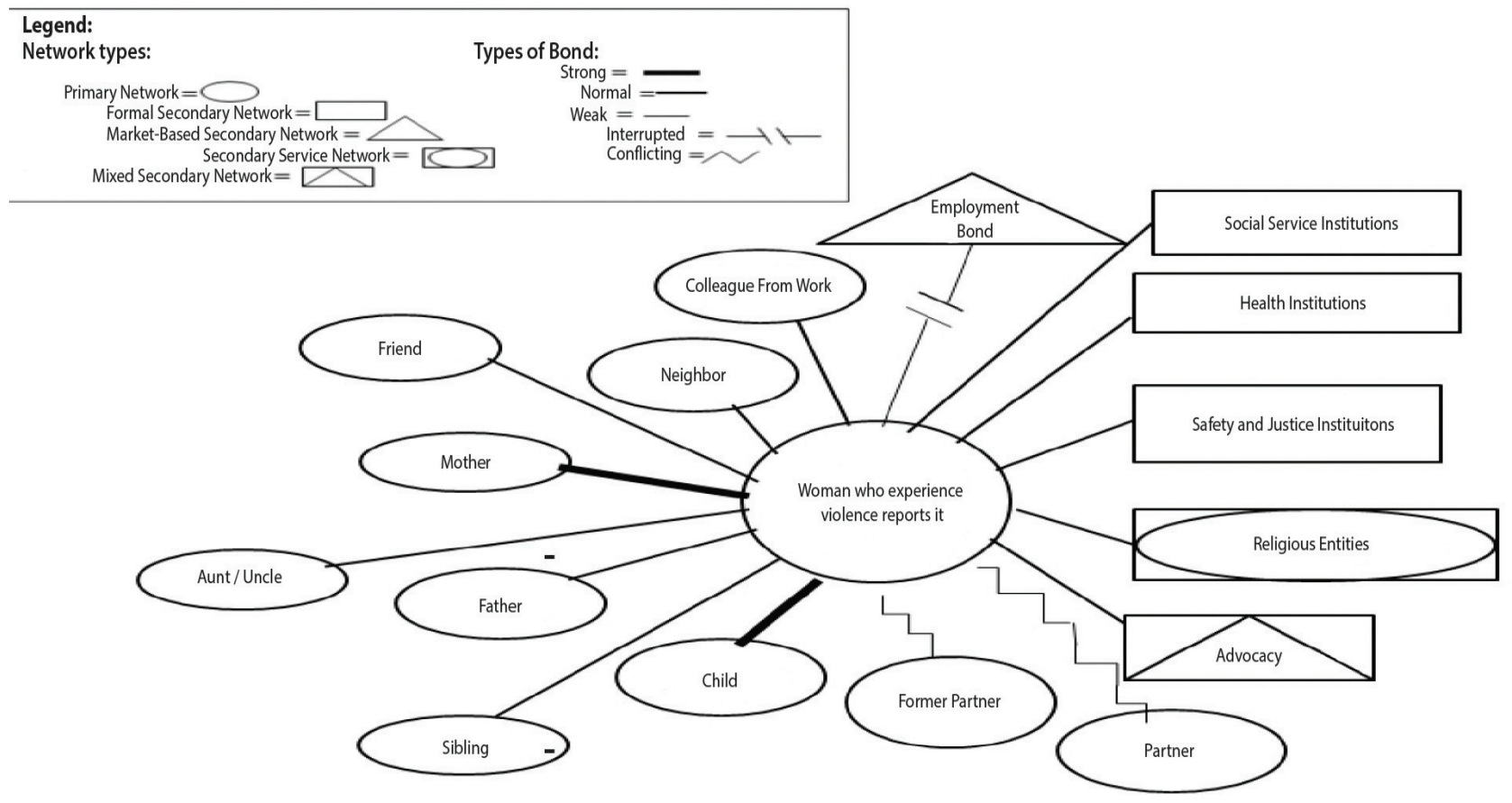

Figure1 - Typical social network of women in the study

As to the type of help they sought to cope with the violent situation experienced, most women mentioned psychosocial help, followed by financial help and information help. They indicate the search for psychosocial help in the primary network through the female members (mother, sister and daughter). The male figure highlighted in her primary network, such as father, brother and uncle, is linked to financial help. The information help based on the primary network comes from co-workers, friends and siblings. The current boyfriend/partner is another social network member the woman counts on to seek help in the violent situation she is experiencing in her former relationship with her ex-partner.

The analysis of the women's maps revealed the discrete presence of the health services in the composition of the secondary social network (which the women called: health service, Mobile Emergency Care Service, general hospital, psychiatric sector, Emergency Care and Family Health Strategy) and, when mentioned, the relationship between the health professional and the woman experiencing violence was characterized as fragile and, sometimes, limited to the punctual complain of violence, physical injury and incapacity (to move, see, hear) it caused. Thus, the health professional is objectified as the health service, which highlights the impersonality. As observed, it is difficult for the health professionals and the women to see the health service as a space for prevention and rehabilitation after the violence.

\section{Discussion}

The mapping revealed a typical social network in which the primary network is more present than the secondary network but, despite being constituted by significant relationships, sometimes demonstrates limitations. The primary social network represents the cultural hub of the social reality, the context in which the essential values for the individuals' life are produced and learned, which are assumed as a fundamental reference point for the people's orientation and action in society ${ }^{(7)}$. The analysis of the interviewees' primary social networks identified an average 2.5 members whom the woman can truly count on and seek help from in violent situations, which is in accordance with research results ${ }^{(6)}$. This help ranged between 1 and 6 people from the primary and secondary network, externalizing the limited possibility of help/support in the violent context.

In the first place, the woman's search for help happens in her own social context, in the family and network of friends, which sometimes does not always represent help to them, but violence, as they feel that their privacy has been invaded(9). Nevertheless, it is verified that the low range of the network interferes in the women's perception of their ability to change their life, being yet another reason to perpetuate the daily reality of violence ${ }^{(6)}$.

The situation of violence the women experienced mobilizes them to access the social network. The women in the study are going through the denouncement 
process, they are attempting to access a secondary network, while a primary network is already present. The women demand the secondary network at an eventual and punctual moment. They did not experience this demand in the process, but only in the problem, i.e. violence and its repercussions in the women's life and health.

The secondary network the women referred to most predominantly was the formal network, which establishes exchanges of rights from a perspective of social wellbeing. The women who indicated rupture with the service sector network (employment bond) related this occurrence with the negative inference of their former partner and with the episodes of violence experienced in this social space.

In the context of violence, the social network members are moved to help the woman, who demand financial, psychosocial and information help as, in most cases, she is weakened because she needs to take important decisions in her life, such as remaining in the violent relationship or separating from her partner, protecting her children from that violent environment, having conditions to survive, recovering her employment bond, restoring her dignity as a woman, among so many others. At the same time as she looks for and expects this help, however, the social relations are interrupted; motivated by jealousy, domination and submission, resulting in social isolation, which the partner intentionally provoked. This caused the woman's financial dependence on her social network, as the partner also discourages and hampers any employment bonds.

Based on the women's reports, it was verified that, the longer they had lived with their partner, the weaker was their bond with the social network and, consequently, the more restricted was the help and/or support the networks offered. In most cases, this situation of constraint in the social relations was established through the shame of experiencing the violence and sharing this experience with other people, out of fear of retaliations by the partner against themselves and their family, and of being judged for the choices and decisions in the conflicting relationship with the partner.

The women in the study live with threats, insults and daily aggressions due to fear and shame and, afraid of judgments, they continue in the social relationship with the partner. At a given moment in their lives, however, whether to protect themselves or their children, they decide to look for help in their social network to break with this violent experience. In this passage, many social relations are ruptured between the woman and her network, as these are bonds the partner considered unwanted. When she decides to denounce the violence, however, she puts in motion network members who can offer her some kind of help to experience this process. Punctually, in this decision to seek help, the woman puts the secondary network in motion, although the approach of this network is specific and isolated in each institution, such as the health sector with a focus on the physical injury that damaged her health, the legal sector offering support to protect and/or maintain the guardianship of the children and, from the financial perspective, to share the material goods the couple holds in common. The limitation of the secondary social network is contextualized to the development of an articulated network activity, indicating the woman's pilgrimage in searching, often solitarily, help/support in institutions that should theoretically work across sectors, in view of the complexity of the theme violence.

In view of the fact that violence is used as a tool to solve conflicts and do justice with one's own means, the women express that they did not seek/counted on the help of a social network member to cope with the violent experience, as the reaction of the social network to the woman's experience could be to strike back with violence. In addition, according to the women, not seeking help implied not presenting demands that only relate to them and their partner to other people and not harming other people's lives with their personal problems. Therefore, they decided not to seek help and experience this process without counting on the help of a primary social network member. This finding supports another study that reveals the women remained in relationships of violence, abuse and control by their partner for many years, with little access to help/support devices(12).

This decision makes the women experience the denouncement and coping with the violence more restrictedly in relation to the social network members, leading to a more solitary and lengthy process of rupture with the cycle of violence, as the different forms of help the people can offer them also become more restricted, in some situation obliging the women to maintain the relation with their partner, considering aspects like her and her children's maintenance and the lack of alternative social relationships in her life world. This results in social isolation, somehow forced by the complex context of the violence.

The demarcation of the emotional support the female primary network members offer and the financial help the male members offer strengthens the gender stereotypes of being man and woman in our society, which 
relegate care and compassion to women, revealing the recognition of oneself in the other (potential to become a victim of the patriarchal system), and the man's role of provider in social relationships, which is not linked to the sphere of feelings and emotions.

Women talk about the violence experienced to close persons, relatives, friends or co-workers, but do not always find empathy and solidarity, mainly when the gender and Family conceptions are very traditional. The families show a contradictory attitude between supporting the woman and advising her to remain in the relationship, strengthening the female position of subordination, minimizing the conflicts between the partners, which remain in the private sphere. Despite these limitations, relatives and friends offer a space of protection and can represent, together with other community services, the main support to resist to the episodes of violence(4).

When referring to the different social network members the women relates to in search of help/ support, the mothers' place in the network and in helping their daughters who are experiencing violence stands out. The women refer to the mother as a wise person who has already experienced this kind of situations. The mothers are particularly important, as the women turn to them to share and request orientation regarding the violence experienced. Nevertheless, they appoint that the mothers tend to reinforce the idea that it is natural for men to be violent, contributing to the reproduction of gender inequalities ${ }^{(8)}$.

In the study under analysis, the women's social network can offer support for them to cope with the denouncement process of the violent experience, granting help and protection and, at the same time, can be the social space where this violence is (re)produced, as the former partner is part of this network of relations that permeate the women's network.

This evidences that being inserted in a social network does not guarantee protection in the context of violence. Thus, the quality of the support the women receive from their social network members is a determinant factor to break with this experience. The quality of the support is related to the possibility that the social network will stimulate/encourage the women's processes of empowerment and autonomy, search for financial independence, demonstration of affection, compassion and care and non-moralistic and judgmental attitude towards the woman's experience. Social network support is a protection factor in the relation between the women's exposure to traumatic events of life in violent situations, protecting them from the negative effects of violence on their mental health. The probability of being assaulted by their partners decreases to the extent that their social support network increases/gets further qualification, also demonstrating the beneficial effects on the coping strategies with violence and the resistance against the partners' domination ${ }^{(13-15)}$.

The health services discretely constitute the women's secondary social network in this study. Similarly, the accomplishment of articulated actions between health and other network services is not expressively related. Isolated actions on the physical sequelae of violence is emphasized. A single service is not capable of giving a satisfactory response to the complexity of the phenomenon but, if addressed from the perspective of work in a network, with the proper articulation of resources and services, it offers the possibility of a multiprofesional and interinstitutional approach, essential to cope with the problem.

The health sector, as one of the nodal points the subjects put to work at times of crisis, needs to be more active in its articulation with the other sectors that direct or indirectly act on the subjects' daily life. The members of a health care network, services and professionals, who not act or do not consider themselves as part of their users' social network, can favor the increasing weakness and fragmentation of these subjects' network ${ }^{(6)}$. Unfortunately, the health professionals are unable to envisage a new posture with a view to including something new and creative that accompanies the demands for a work method in network. The power of the network is related with the quality of the connections and bonds, requiring resources, commitment, objectives, attitudes and motivations directed at the group ${ }^{(16)}$.

\section{Conclusion}

The analysis of the typical social network of women who denounce the experience of intimate partner violence permits concluding that the primary network, despite being constituted by significant social relationships, sometimes demonstrates limited support in situations of violence. There is also a lack of financial autonomy and self-esteem to control/manage their own and their children's life, which makes the women remain in the unwanted social relationship with their partner and maintain their social isolation from the other network members.

The services in the care network for women in situations of violence are not recognized as effective 
help for their social and health demands, as they are punctual services that do not engage in the coping process with the violence. This reveals a fragmented and disarticulated and sometimes inaccessible network that is distant from the women's reality, in line with the recommendations of the public policies in the field of violence against women.

The women still need to recognize the health area, and particularly primary health care, as a space that offers help not only at the punctual moment of the violence, but as a device that can accompany them in the process of breaking with the violence in their lives, encouraging them and presenting them possibilities to live without violence, assuming the control over their lives and decisions. Therefore, the health services and professionals also need to recognize themselves as members of these women's secondary network, creating space for the help to transcend the punctual moment of the aggression, accompanying them in their process of empowerment and emancipation from an experience annulled by the violence.

In addition, it is relevant to recognize the importance of the articulations between the primary and secondary social networks in this complex phenomenon of violence. The primary social network members are present in the women's daily life and can serve as spaces of help or reproduction of violence. The health professionals, including the nursing team members, are responsible for recognizing the social actors that constitute the women's social networks, with a view to permitting significant help in the women's relational context and identifying possible members that do not relate with them beneficially.

Weaving networks to cope with the violence demands the concentration of attention on resources and positive possibilities that offer some kind of support, free from judgments and patriarchal conceptions, respecting the women's projects, acts and decisions in the context of their experience. Therefore, this study contributes to the possibility of support/help deriving from the insertion of the theoretical framework of the social network into the ministerial political proposals to cope with violence against women, based on the women's experience from the perspective of care practices and based on the principle of comprehensive health care and assistance.

\section{References}

1. Gomes NP, Silveira YM, Diniz NMF, Paixão GPN, Camargo CL, Gomes NR. Identificação da violência na relação conjugal a partir da estratégia saúde da família. Texto Contexto Enferm. 2013;22(3):789-96.

2. Hesler LZ, Costa MC, Resta DG, Colomé ICS. Violência contra as mulheres na perspectiva dos agentes comunitários de saúde. Ver Gaúcha Enferm. 2013;34(1):180-6.

3. Brasil. Secretaria de Políticas para as Mulheres. Política Nacional de Enfrentamento da Violência contra as Mulheres. Brasília: Secretaria de Políticas para as Mulheres; 2008.

4. Meneghel SM, Bairros F, Muller B, Monteiro D, Oliveira LP, Collaziol ME. Rotas críticas de mulheres em situação de violência: depoimentos de mulheres e operadores em Porto Alegre, Rio Grande do Sul, Brasil. Cad Saúde Pública. 2011;27(4):743-52.

5. Santos MA, Vieira EM. Recursos sociais para apoio às mulheres em situação de violência em Ribeirão Preto, SP na perspectiva de informantes- chave. Interface Com Saúde Edu. 2011; 15(36):93-108.

6. Dutra $M L$, Prates $\mathrm{PL}$, Nakamura $E$, Villela WV. A configuração da rede social de mulheres em situação de violência doméstica. Ci Saúde Coletiva. 2013;18(5):1293-304.

7. Sanicola L. As dinâmicas de rede e o trabalho social. Napoli: Liguori Editore; 2008.

8. Souza MHN, Souza IEO, Tocantins FR. The use of social network methodological framework in nursing care to breastfeeding women. Rev. Latino-Am Enfermagem. 2009;17(3):354-60.

9. Santi LN, Nakano MAS, Lettiere A. Percepção mulheres em situação de violência sobre o suporte/ apoio recebido em seu contexto social. Texto Contexto Enferm. 2010;19(3):417-24.

10. Fontanella BJB, Ricas J, Turato ER. Amostragem por saturação em pesquisas qualitativas em saúde: contribuições teóricas. Cad Saúde Pública. 2008;24(1):17-27.

11. Schütz A. Sobre fenomenologia e relações sociais. Petrópolis: Vozes; 2012.

12. Evans MA, Feder GS. Help-seeking amongst women survivors of domestic violence: a qualitative study of pathways towards formal and informal support. Health Expectations. 2015 Jan 2. doi: 10.1111/hex.12330. [Epub ahead of print]

13. Kapadia MZ, Saleem S, Karim MS. The hidden figure: sexual intimate partner violence among Pakistani women. Eur J Public Health. 2010;20(2):1648.

14. Glass N, Perrin N, Campbell JC, Soeken K. The protective role of tangible support on post-traumatic 
stress disorder symptoms in urban women survivors of violence. Res Nurs Health. 2007;30(5):558-68.

15. Goodman LA, Smyth KF. A call for social networkoriented approach to survivors of intimate partner violence. Psychol Violence. 2010;1(2):79-92.

16. Gomes NP, Bomfim ANA, Diniz NMF, Souza SS, Couto TM. Percepção dos profissionais da rede de serviços sobre o enfrentamento da violência contra a mulher. Rev Enferm UERJ. 2012; 20(2):173-8. 